\title{
Transforming school culture through inquiry-driven learning and iPads
}

\author{
Kurt Thumlert, Ron Owston and Taru Malhotra \\ Faculty of Education, York University, Toronto, Canada
}

\begin{abstract}
Purpose - The purpose of this paper is to provide an overview of a commissioned research study that analyzed a schooling initiative with the ambitious goal of transforming learning environments across the district by advancing innovative, inquiry-driven pedagogical practices combined with 1:1 $\mathrm{iPad}$ distribution. The paper explores impacts of the initiative on pedagogical innovation, twenty-first century learning, and related impacts on professional learning, collaboration, and culture change in the pilot schools analyzed in the study.

Design/methodology/approach - A multi-dimensional case study approach was used to analyze how the initiative was implemented, and to what extent teaching, learning, and professional cultures were transformed, based on action plan inputs and "change drivers". Research methods included structured, open-ended interviews conducted with randomly selected teachers and key informants in leadership roles, focus groups held with students, as well as analysis of policy documents, student work samples, and other data sources.

Findings - The authors found evidence of a synergistic relationship between innovations in inquiry-driven pedagogy and professional learning cultures, with evidence of increased collaboration, deepened engagement and persistence, and a climate of collegiality and risk-taking at both classroom and organizational levels. Based on initiative inputs, the authors found that innovations in collaborative technology/pedagogy practices in classrooms paralleled similar innovations and transformations in professional learning cultures and capacity-building networks. Practical implications - This initiative analyzed in this paper provides a case study in large-scale system change, offering a compelling model for transformative policies and initiatives where interwoven innovations in pedagogy and technology mobilization are supported by multiple drivers for formal and informal professional learning/development and networked collaboration. Challenges and recommendations are highlighted in the concluding discussion.

Originality/value - The transformative initiative analyzed in this paper provides a very timely case-model for innovations in twenty-first century learning and, specifically, for enacting and sustaining large-scale system change where inquiry-driven learning and technology tools are being mobilized to support "deep learning", "new learning partnerships", and multilevel transformations in professional learning (Fullan and Donnelly, 2013). This research advances scholarly work in the areas of twenty-first century learning, identifying relationships between technology/pedagogy innovation and professional capital building (Hargreaves and Fullan, 2012).
\end{abstract}

Keywords Professional learning, Collaboration, Professional capital, Whole system transformation,

Technology innovation, Inquiry-based learning, Pedagogical innovation

Paper type Research paper

Recent educational literature asserts that traditional forms of education designed to meet late twentieth century purposes are no longer adequate to the opportunities and challenges facing twenty-first century learners - particularly in relation to changing practices in the domains of communication, work, citizenship, and cultural participation (Cope and Kalantzis, 2009; Fullan and Donnelly, 2013). Threads linking this literature include descriptions of dramaticallytransformed sociotechnical landscapes that require schools to adapt to a wide array of digital tools, and to respond strategically to changing forms of literacy and learning today, as well as respond to the increasing cultural and linguistic diversity characterizing contemporary societies (Lotherington and Jenson, 2011). Terms like "knowledge economy" and "creative

This study was supported by the Council of Ontario Directors of Education and the Ontario Ministry of Education. The authors wish to thank Herb Wideman and Gerry Smith for the valuable contributions they made to the report upon which this paper is based. The authors are also grateful to the district educators and students for their participation.
Received 5 September 2017 Revised 1 December 2017 Accepted 17 January 2018

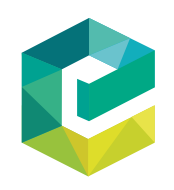

Journal of Professional Capital and Community Vol. 3 No. 2,2018 (c) Emerald Publishing Limited 2056-9548 DOI 10.1108/JPCC-09-2017-0020 
JPCC

3,2

80

economy" (Peters and Araya, 2010) are frequently invoked to identify not simply new forms of economic value, but emerging knowledge-making practices and new forms of collaborative, creative cultural design: these are the powerful dispositions and competencies required for learners to flourish in the twenty-first century. At the same time, social justice matters are interwoven within these changing landscapes, as twenty-first century literacies are becoming, increasingly, new axes of inequality and social differentiation. And while powerful twenty-first century competences are central to individual and collective success in globalized economies, they are also the very tools for critiquing and transforming the structures and systems that students may find themselves within (Cope and Kalantzis, 2009). As other theorists (Luke et al., 2017; Thumlert, 2015) remind us, ecological, social justice, and ethical exigencies, today, require us to rethink education not as a developmental system that gradually "prepares" student for later life, but as a dynamic vehicle for situating learners in agentive roles in the present, where students are (re)understood as actors capable of engaging real-world controversies and critical learning adventures using authentic tools in real-world contexts.

In response to these challenges, scholars have identified new pedagogies and deep learning forms, including models of collaborative, inquiry-driven learning responsive to new tools and emerging media ecologies (Dede, 2014; Fullan and Langworthy, 2014), as well as rich learning tasks "connected" to networked communities of practice proliferating outside of schools (Ito et al., 2013). Still, in an era when proponents of educational innovation are advancing digitally-mediated learning environments supportive of new pedagogies where knowledge construction is central, standardizing accountability mandates may continue to work, antagonistically, to undercut the potential of these novel technology/pedagogy models, even as student disengagement within schools becomes a matter of increasing concern (Jenson et al., 2016; Hébert, 2015). In this context, Chris Dede (2015) suggests that "the most dangerous experiment we can perform is to keep our current systems of schooling in place."

In this paper, we examine an ambitious attempt to challenge "current systems of schooling," with the aim of fundamentally transforming teaching and learning through a holistic, multilateral, and evidence-based approach to district-wide system change. Specifically, we provide snapshots from a commissioned research study that analyzed the first two-years of a board-wide schooling initiative in Ontario: an initiative with the ambitious goal of transforming learning environments and professional cultures across the district by connecting innovative pedagogical practices with innovative tool use.

Unlike educational reform pushing "technology integration" as a single driver to enhance existing forms of instruction, this large-scale initiative activated multiple drivers to support transformative change in pilot schools, including: personalized 1:1 technology integration in combination with inquiry-based learning (IBL), support for professional learning/development, and "new leadership" strategies that invited teacher agency and collaboration as an enabler for building professional capital and new learning cultures (Hargreaves and Fullan, 2012). Key pedagogical aims of the initiative, outlined in the action plan, were to support deep learning pedagogies, student knowledge creation, and twenty-first century digital competences, so as to ensure all students meet the challenges of rapidly changing environments outside of school (Action Plan, 2014[1]).

As an effort to enact transformative change, focusing on multiple institutional variables simultaneously and multilaterally, this initiative provides a case study for other transformative initiatives where technical innovation is interwoven with innovations in pedagogy. In what follows, we critically explore how, and to what extent, transformative technology/pedagogy practices were communicated and positioned for scaling and sustainability. As a study in system change, we hope our analysis can feed-forward to support further innovations in policy. Equally importantly, how might lessons from this innovative initiative help us forestall the eventual erosion of transformed practices? 


\section{Positioning our study: transformative ecologies}

Scholars working in area of technology and education have, over the past decades, pointed out that technology-based reform initiatives often position digital technologies as "additive" resources or "objective," "neutral" tools that can accelerate and enhance instructional practices (de Castell et al., 2002; Dawson and Heinecke, 2004). The logic of enhancement informing such initiatives may thus take for granted extant curricular suppositions, teaching roles, and the very "technologies of practice" that script how actual material tools/technologies are used, and to what ends (Nordkvelle, 2004; Thumlert et al., 2015). As Christensen et al. (2008) have popularized this discussion, digital innovations are frequently incorporated as "sustaining technologies" which are organizationally adapted to streamline prevailing methods without challenging inherited aims and routines, standardized role-functions among actors, or governing assessment models. Such technology-based reform innovations may, paradoxically, contribute to reproducing traditional educational forms.

By contrast, many scholars have challenged the view that transformative uses of technology can take hold in schools without coordinated efforts to support innovative pedagogies, professional leaning, and wider ecological changes in school culture (Owston, 2007; Fullan and Donnelly, 2013; Hargreaves and Fullan, 2013). As Toohey and Dagenais (2015) assert, meaningful transformation involves addressing the sociotechnical "assemblages" and conditions that reproduce accepted realities in schools or, alternately, become affordances of change: drivers that stage novel configurations of practice - from innovative policies and narratives about teaching and learning to their embodiment in everyday teaching practices and professional learning cultures (along with new orientations to technology tools, and the different learning practices and assessments that emerge, or become conceivable, under transformed conditions). By implication, large-scale efforts to transform schooling systems need attend to the same complex "assemblages" that condition beliefs and realities in schools. If the "drivers" of system reproduction are ecological and holistic, embodied and encultured, then so need be the drivers and affordances of system change.

Helpfully, scholars focusing on system transformation in schools have noted that the command-and-control forms of administration characterizing twentieth century schools are shifting toward more heterarchical leadership models (Peters and Araya, 2010; Kontopoulos, 1993) - models that encourage networked professional learning, collaborative teacher inquiry, and the agentive dispositions necessary for teachers to takes risks and share responsibility in reshaping their own professional cultures (Hargreaves and O'Connor, 2017; Hargreaves and Fullan, 2012; Donohoo, 2017; Hattie, 2015; Fullan and Donnelly, 2013). Here, Zeichner (2002) and Drew et al. (2016) suggest that "successful innovation" in schools requires a "culture of inquiry" that permeates not just classroom learning, but professional learning as well: a culture that recognizes "teachers' voices" and their creative capacities as active partners in system change. Indeed, as research has shown (Fullan and Langworthy, 2014; Drew et al., 2016), conditions for sustainable innovation are enacted when professional inquiry and professional learning are enacted as part of an ongoing, collaborative feedback cycle.

At the same time, Fullan and Langworthy (2014) also point out that the "contexts outside of schools" are, today, more compatible with "the confluence of new pedagogies (new partnerships, deep learning tasks, and pervasive digital resources)" (p. 49). In these networked settings, traditional "instructionist modes" of pedagogy critiqued decades ago by Papert and Harel (1991) and the New London Group (1996) are being increasingly challenged by educational policies responsive to sociotechnical shifts outside of schools, as well as by innovative technology-supported pedagogies that position actors, within schools, as authentic knowledge makers.
Transforming school culture 
JPCC

3,2

82

\section{Study context and research questions}

It is in these shifting contexts that we situate our study, conducted during the second half of the 2015-2016 school year. This paper provides an analysis of the first phases of a five-year initiative, one with the ambitious goal of transforming learning across the district by integrating new pedagogical practices (IBL) with innovative technology use, including 1:1 iPad distribution. The focus of our research was a family of seven pilot schools which were in the second full year of initiative implementation (grades 4 through 8). The schools were located in an urban area of the district characterized by low average incomes, a high percentage of single-parent families, high unemployment levels, a high proportion of residents with low educational levels, and relatively low home ownership rates. Our goals were to examine early impacts of the initiative on transforming teaching practices and deepening student learning through inquiry-driven practices organically interwoven with digital tool use and twenty-first century competences (AP). While 1:1 iPad mobilization and technology infrastructure played a central part in the initiative action plan, it was clear that pedagogical transformation was the cornerstone of the initiative, informed by the view that significant innovation can only happen when new structures are holistically established (AP; Canuel, 2013).

The initiative's theory of action was informed by the work of Ontario educational scholars like Michael Fullan and Ontario Ministry of Education (2013) documents advancing personalized, student-directed, IBL. To contextualize our analysis below, the theory of action instantiated or translated many aspects of Fullan and Langworthy's (2014) and Fullan and Donnelly's (2013) work on deep learning (rich tasks, new pedagogical capacities and learning partnerships, the "Six Cs," and multilevel change theory).

\section{Research questions}

We developed a research model based on the board's theory of action (AP). Our research model focused on the relationship between five enablers of change, including: support for professional learning/development and culture change, professional support for administrators, digital hardware and software for classrooms, technical support for schools and teachers, and funding from the board and Ontario Ministry of Education actors. Specific research questions focused on if, how, and to what extent the implementation of the action plan, IBL and the infusion of technology through 1:1 iPad distribution was effective in enacting initiative goals.

In our original report, we reviewed existing literature and empirical research relating to initiative rationale: in particular, we reviewed research on different forms of IBL and one-to-one technology use in schools. Our literature review, interviews with key actors and leadership staff, and analyses of the action plan and related policy documents indicated that the school board had developed an initiative that was supported by the research and literature, including Ministry documents. Extensive research within and outside of Ontario and Canada suggests that IBL, supported by 1:1 technology tools, provides an excellent footing for supporting twenty-first century competences. However, there is the need to ensure that there is fidelity of implementation when inquiry-driven pedagogies are put into practice, and that technology tools are used in innovative ways that encourage deep learning and knowledge construction, and are not being used to merely reproduce standardized instructional forms.

Our research questions were organized by their domains of action in relation to holistic school change: the school/leadership level, the teacher level, and the student level, though we ultimately found these categories to be interactive and mutually-imbricated in terms of telescoping initiative goals.

\section{System level questions}

How did key leaders and principals promote a culture where actors at all levels of the board could begin to form new learning partnerships (Fullan and Langworthy, 2014) and begin to take agentive roles in implementing and furthering initiative aims? 
Teacher level

To what extent did teachers adopt the action plan and transform their pedagogies, becoming designers and "activators" of deep learning as well as "change agents" (AP; Fullan and Donnelly, 2013; Hattie, 2009)? In particular, how and to what extent did teachers promote deep learning and collaboratively participate in building a new learning culture (AP)?

\section{Student level questions}

What evidence was present of transformed learning environments, new teacher/student partnerships (Fullan and Langworthy, 2014), and rich inquiry-driven tasks supporting fluency with twenty-first century tools and competences; and what evidence was there of increased student engagement, persistence, and deeper learning?

Given the scale of our original research report, and for the purposes of this paper, we will narrow the scope of our present discussion to the initial impact of the initiative on school culture, professional learning/development and professional capital building (Hargreaves and Fullan, 2012), with related evidence of impacts on teaching and learning practices using IBL and iPads. Detailed analysis of administrative drivers, funding/external institutional supports, and initiative "roll-out" will be examined elsewhere. Analyses of student work samples will be referenced, below, only in relation to evidence of transformed learning cultures, pedagogical innovation, and related challenges and recommendations.

\section{Research methodology}

We investigated our research questions using case study methodology. This approach to inquiry addresses both descriptive and explanatory questions, and the rich data it generates makes possible a detailed, nuanced, and well-contextualized understanding of how and why a program works in a particular setting (Yin, 2006). Multiple data sources were chosen to provide converging lines of evidence that triangulate in order to make our findings as robust as possible (Patton, 1990). These sources included teacher and key informant interviews, student focus groups, teacher and student surveys, publicly-available policy and planning documents, and student work products and artifacts. Our data collection was integrated with that undertaken by the school district as part of their own ongoing research and monitoring of the initiative. This had a significant impact on the extent and types of data we were able to collect. The impact is discussed next in the description of the procedures followed for each group of participants.

\section{Participants}

Teachers. In total, 14 teachers from six of the seven schools were interviewed on site. The teachers interviewed were selected randomly using a stratified sampling procedure to ensure that two teachers from each of the five grades (grades 4-8) were part of the sample. The two remaining teachers interviewed had no specific grade teaching responsibilities: a special education teacher who worked in other teachers' classrooms and also withdrew students for special instruction; and a champion/resource teacher who collaborated with and coached other teachers around IBL and iPad applications to teaching, and provided digital citizenship and research skills instruction. All but two of the teachers were in their second full year of being in classrooms with a complete set of iPads; and all but two had been teaching for seven or more years. Nearly all had spent half or more of their teaching careers at their current school.

Semi-structured interviews probed all aspects of teachers' use of IBL pedagogy through the phases of students' inquiry work, from project initiation to student presentations and summative evaluations. They also addressed teachers' observations of students' work practices in inquiry learning, and its impacts of student engagement, persistence, knowledge building, and twenty-first century skills development. Teachers' perspectives on the role, value, and affordances of iPad technology in IBL and other forms of learning, 
JPCC

3,2

84

how iPads were employed in their classrooms, and their effect on student learning practices, twenty-first century skills development, and learning outcomes were also examined in depth. Teachers were also asked about if and how IBL and 1:1 technology infusion had augmented or transformed their pedagogical practices and professional growth. Perceptions of the educational advantages and the limitations of IBL and iPad integration were taken up, and their professional learning experiences supporting initiative goals explored. All interviews were recorded and transcribed for subsequent analysis.

Additional data about teacher attitudes and perspectives on IBL and iPad integration and related professional development were gathered from an online survey of teachers that the school district conducts on an annual basis. Only the data from the 39 respondents teaching in 1:1 classrooms in grades 4-8 in the seven schools studied were considered. The survey questions largely consisted of Likert-scaled items, with a few having open-ended answer options. We had initially planned to conduct our own teacher survey but this was not permitted by the school board. We were allowed to submit additional questions for the district survey, and some of them were accepted. These addressed teacher attitudes about having iPads in their classrooms; the learning purposes and formats digital tools were applied to; and professional development activities and opportunities and support for iPad use.

Key informants. While we were not permitted to conduct our own interviews of program leaders and district and school administrators about the initiative (with one exception), a few additional questions we proposed were added to the protocol for an annual interview conducted by district researchers of those deemed "key informants" on the initiative. The five key informants interviewed included three principals from the seven schools, a senior consultant responsible for project implementation, and the superintendent responsible for the family of schools which included our seven sites. These open-ended semi-structured interviews were provided to us in anonymized form and we had them transcribed. The key informants were asked what they considered to be the major successes and challenges of the initiative over the past year; their understanding of the theory of action; changes seen in instructional practices; strategies used by teachers to integrate technology into their classrooms; changes in student learning; and the nature and extent of professional learning activities and capacity building over the year. In order to obtain more details on the specifics of the project action plan and implementation policies, an additional telephone interview of the executive superintendent with overall responsibility for the project was conducted by two evaluation team members. This interview was also recorded and transcribed.

Students. As mentioned above, a discussion of the findings on student outcomes is beyond the scope of this paper. Nevertheless, a brief overview of the procedures followed to collect student data is pertinent. A total of 44 students from 11 grade $4-8$ classes in six of the schools participated in focus groups led by a member of the research team and consisting of four participants in each. We obtained student responses to the district's annual online student survey that was administered in late spring 2016. Student work samples collected from the classes of the teachers interviewed were collected and subjected to both a narrative and a holistic analysis. These were obtained at the end of the school year; teachers were asked to submit samples of long-term (i.e. longer than one week) student inquiry products or learning demonstrations such as a presentation or other artifact.

\section{Document collection}

Relevant publically-available documents related to the initiative were collected, coded, and analyzed. Documents included the district action plan for the project, school board minutes, project reports, policy documents, memos, and various papers describing the project from early stages of implementation. Government policy documents that were referenced in project reports were also reviewed. 
Work samples analysis

Samples of student project work were collected. Teachers were asked only to submit student work that was based on projects that lasted a week or more. The work consisted of written reports and multimedia presentations. Work was coded using criteria developed by SRI International (www.itlresearch.com/research-a-reports/2011-itl-research-design-and-methods) to specifically assess student work products for evidence of twenty-first century learning competences. Coding was carried out by a team of three teachers from a different school board who were trained by the principle investigator. Training continued until the teachers had close to 100 percent inter-rater reliability. All teachers coded all of the samples and average scores of the three ratings were used.

\section{Qualitative data analysis}

All qualitative data were analyzed using constant comparative procedures (Strauss and Corbin, 1990) aided by the qualitative analysis software program, NVivo. The process involved reading and re-reading the transcripts and documents and coding relevant themes that emerged. As the coding continued, new codes were added and some were merged. The process continued until all coding categories were saturated. At this point summaries were written of the categories upon which the final write-up was based.

\section{Findings: enacting ecological transformations}

We begin with findings relating to professional learning and transformations in school culture. We then explore findings on the initiative's impacts on transforming pedagogy/technology and assessment practices; on new learning partnerships, student engagement, and twenty-first century competences; following this we address how 1:1 iPads and pedagogical innovations supported a culture of inclusivity and participation.

\section{Competency drivers: professional learning/development and culture change}

In a comprehensive analysis of 59 cases studies, Owston (2007) identified "essential conditions" for sustaining large-scale innovations. These conditions included teacher and student enthusiasm for initiatives, strong support for teacher professional development/learning, and active support of initiatives by principals. Owston's conclusions are shared by Coburn (2003) and Dede (2016), who further state that in order to sustain/scale transformative initiatives, they must result in deep and lasting change in culture: the beliefs, norms, and valued principles of the initiative need be established across many schools; and ownership of the initiative must shift from central board authority to schools and teachers. Fullan and Donnelly (2013) add that continuous formal professional learning - with specific goals to ensure change - need be organized and embedded in practice; and there must be follow-up professional learning/development supportive of a culture of learning characterized by collegiality, sharing, and risk-taking.

These essential conditions for change in fact aligned well with the action plan's fundamental strategic inputs, and in our findings, all of these conditions were largely in play or emergent. Here, as a discursive device (Latour, 2005), the initiative's action plan was clear and rhetorically compelling in articulating vision and rationale in direct relation to twenty-first century learning aims and purposes.

Using data from policy documents, interviews with key actors and teachers, and teacher surveys, we identified a constellation of "competency drivers" (Fixsen, Blase, Naoom, and Duda, 2015) - the professional learning opportunities and policies - that were implemented to support changes in professional learning and the uptake of new technology/pedagogy practices. From these sources, we mapped a rich variety of formal professional learning 
JPCC

3,2

opportunities; we also identified a very healthy climate for informal, ad hoc collegial sharing, supported by new technology networks.

Specifically, the formal professional development supports and strategies identified in our findings below are, in the literature, generally regarded as best practices for teacher development, and included PA day events; school-organized professional learning activities; lunch-and-learn sessions; formal collaboration with external partners and twenty-first century learning experts; and discussion/debriefing at staff meetings and other knowledge-sharing opportunities. Initiative-focused conferences and workshops were also organized, dedicated to modeling and sharing IBL and/or iPad best practices and resources. Embedded coaching by initiative champions and mentoring by twenty-first century learning experts were also distinguishing features of the initiative: here, teachers identified embedded mentoring and continuous coaching as very valuable for ongoing professional learning.

Additionally, instances of Ed Camps, run for teachers on PA days, allowed teachers to collaborate extensively in breakout groups, with the support of twenty-first century learning mentors. These events were very well received by teachers. As one teacher reported: "It's fabulous because [these events allow] someone who really understands the inquiry model and technology to be a part of a conversation and provide insights. It also allows someone who doesn't [yet understand] to be able to learn from that, but without any particular person being deemed the expert in the center of that conversation."

Internal conferences and workshops also proved valuable for teachers who found it beneficial to hear other colleagues present concrete examples of how iPads were being activated in content areas. Other workshops organized by the board (e.g. Digital Media through the Arts) demonstrated applied use of multimodal iPad tools in content areas, and were lauded by teachers. Said one teacher: "[The workshop] gets you thinking about how to engage the kids in your subject matter, but through an arts umbrella and it could be anything, music, drama and dance [...] it's fantastic."

The board's action plan recognized the basic principles of contemporary literature on professional learning. Wei et al. (2009) summarize these, stating that professional learning should be intensive, ongoing, and connected to practice; should focus on student learning and address specific content aims (in IBL, this also means supporting students to make deep connections with "vital ideas" in the curriculum); and building strong collaborative relationships among teachers.

Indeed, there was broad agreement that new network tools (Google Drive, Google Classroom, Apple TV) had made collaborating with colleagues and external experts much easier. Though teachers generally shied away from using the board's official social media tool, we found ample evidence of teachers mobilizing social media like Twitter to establish their own informal learning communities. As part of this networked professional learning ecology, some teachers also used social media, YouTube, and their own blogs to showcase student works (e.g. culminating inquiry products, student-produced videos, and so on). One teacher who had presented at a district-wide initiative conference developed a "personal learning circle" using Twitter, and reported that "within a month I'd been able to build a professional learning community of at least 15 reliable peers."

While teachers reported a very favorable climate in their schools surrounding the initiative in terms of professional learning/development, teachers unanimously desired more formal professional learning focusing directly on IBL and iPads, and specifically on how to better mobilize new technologies in relation to IBL in their content areas, so as to "realize the full potential" of these new pedagogical capacities.

Beyond formal professional learning, there was strong evidence of teachers forging collaborative connections with other teachers, or enlisting the support of champions, to build and circulate professional capital (Hargreaves and Fullan, 2012), to seek out and share models and resources (e.g. teacher book clubs focusing on IBL; informal app sharing; 
showcasing student-projects through social media), and move initiative aims forward. Initiative champions and embedded coaches were valuable in helping teachers make the transition from traditional instructional methods to IBL. Initiative champions themselves reported that they were not simply teaching teachers, but were actively engaged in ongoing professional development and academic conferences, and then modeling new opportunities like "maker spaces" and coding literacies.

These examples of self-directed professional learning articulate Hargreaves and Fullan's (2013) concept of professional capital, which advances that more than "human capital" knowledge, skills, practical know-how - are required to mobilize deep changes in systems. Innovations need be further abetted and amplified by forms of social and decisional capital: continuous practices of learning, inquiry and communication where teachers assume roles as researchers, connecting local, formative feedback to emerging opportunities and new models, and where new knowledge/resources are circulated within the community.

If human capital refers to the given stock of practitioner knowledge and skills, these other dimensions of professional capital (social and decisional) are vehicles for enacting ongoing change, for making informed judgments/critical decisions within shifting contexts, and for building wider cultures of learning, communication, and expertise. In these contexts, teachers analyze evidence of student learning, modify pedagogies, and create a multilevel culture of learning where these dimensions of capital building and professional learning/development operate organically to reciprocally transform professional learning cultures.

Clear evidence of professional capital building was present in the first years of project implementation, and it encouraged deeper relationships between formal professional learning/development and informal networks supportive of the emergent collaborative learning cultures. Significantly, as we will explore in following sections, we found indications of a synergistic relationship where student inquiry and collaborative knowledgemaking in classrooms was just one domain, or relay, in a wider emergent culture of learning permeating the entire pilot-school ecology.

Indeed, for most of the teachers interviewed, collaboration with colleagues was of critical importance in developing new pedagogical capacities and learning cultures: as one teacher stated:

You have to collaborate when doing [the initiative]. You have to. You can't be an expert on everything and you certainly can't be an expert on [every aspect of] technology. So, it naturally forces you to say, "Hey, what app are you using in science? How would this work for me in geography? Or how can I take Explain Everything but use it differently?

In interviews and surveys, it was found that the desire for new knowledge/models led most teachers to markedly increase their degree of collaboration with peers relative to past practices. One school principal observed that teachers who previously felt they had little to offer felt they had more to share after developing knowledge and skill with iPads and IBL, and with a common goal in place, there was more collegial participation and sharing among teachers.

Finally, Owston (2007) found that principal advocacy was a distinguishing feature in the most innovative districts - and an essential condition if innovative initiatives are to be sustained. In interviews with principals and teachers, it was clear that this condition for initiative uptake and sustainability was met: strong principal support was reported in all pilot schools - with related efforts by local administrators to "lead from the middle" (Hargreaves and Ainscow, 2015). Not only did we find evidence that principals in pilot schools championed the initiative, they were also able to shape the direction of new pedagogy/technology practices alongside teachers. Many teachers described how their principals and vice-principals provided them time to research and communicate ideas with colleagues, how they supported risk-taking, and teachers noted that principals were actively engaged in their own professional learning throughout the year. 
JPCC

3,2

88

It was clear from teacher interviews that principals were highly supportive of teachers taking collaborative "change agent" roles in co-implementing the initiative, and creating "new learning partnerships" with students and other teachers.

\section{Impacts of inquiry-driven learning: transformed roles and practices}

We utilized data from multiple interview sources (teachers, administrators, champions, and student focus groups) as well as teacher and student surveys to inform our analysis of IBL implementation and related use of technology tools, addressing the possible effects and outcomes in classroom practice, as well as impacts on learning cultures in pilot schools.

In assessing the adoption of IBL, we examined if IBL was being implemented in ways that remained true to best practices described in the literature. In examining fidelity of implementation, we wanted to determine not only if IBL was being utilized, but to what extent it was being adopted in optimal forms of practice - forms that might realize the potential of IBL not simply to engage students, but to support students' capacities to engage living research questions and controversies, maximize knowledge-making and self-efficacy, as well as support continuous reflection upon inquiry methods and processes (Friesen and Scott, 2013).

Teachers indicated that the conjunction of 1:1 iPads and IBL induced a general, if sometimes gradual, shift away from more traditional forms of direct instruction - due not only to innovations in pedagogy, but also due to the affordances and capabilities of new media. Technology/pedagogy innovations were seen to activate more student-directed, collaborative and project-based learning, and teachers indicated that they themselves were assuming new identities as co-learners while moving away from traditional roles as conduits of predetermined content knowledge. At the same time, teachers perceived, and were thrilled to perceive, students assuming new roles as knowledge makers, becoming "teachers" and "experts" themselves (e.g. when presenting research or culminating IBL projects to peers or wider audiences). Almost every teacher reported that students were taking leadership roles in teaching teachers and peers how to utilize, or maximize, iPad applications.

When teachers were asked how their teaching practices had shifted with the use of new technology/pedagogy practices, and what changes they made in their conceptions of teaching as a result of their experiences, they most often talked about the process of relinquishing control and letting students take roles as collaborative knowledge makers "responsible for their own learning". Saliently, one teacher enthusiastically stated: "I love teaching what I don't know." This statement, and others like it found in our data, indicated that new epistemological relations were emerging in learning communities. And while some teachers indicated varying degrees of (dis)comfort in giving up "control," almost all had to some extent embraced new epistemological suppositions and were enacting "new learning partnerships" (Fullan and Langworthy, 2014) with students. These learning partnerships were validated when teachers observed how students were taking creative ownership of their learning: as one teacher affirmed, "you have to let a 12 year old be the expert in that moment and you have to be the one willing to learn."

Nevertheless, some teachers indicated that students - at least initially - required modeling, guidance or direct instructional intervention, particularly in relation to IBL methods: e.g., how to formulate "good research questions"; how to critically evaluate web-based resources; how to "dig deeper"; how to plan, organize, and analyze; and how to "think for themselves" or "take initiative" in settings requiring students to shift into more autonomous roles.

In changing contexts, teachers were also able to identify tensions between the initiative's new aims and values and the more regulative practices or priorities of traditional schooling which continued to hail them. For example, some teachers identified concerns about: struggling with the need to "cover curriculum"; seeing IBL as a difficult "fit" for math; the need to suspend inquiry-driven learning when preparing students for provincial accountability tests; as well as (in rarer cases), situations where students themselves, habituated to more passive forms of 
instruction, signaled uncertainty regarding inquiry-driven practices. We suggest that these kinds of tensions be confronted, in professional development/learning contexts, and collaboratively worked through, lest they attenuate efforts to sustain innovations.

While incongruities like these were sometimes identified as obstacles, importantly, in teacher interviews, almost every teacher had adopted the discourse of the action plan, its language of change. Even when some teachers signaled concerns surrounding shifting roles and priorities, they were still fluently speaking within and through the initiative's language of transformation, inquiry, and collaboration. We found this formation of a shared discourse community to be a significant indicator that cultural transformations were indeed taking place, and that new professional identities were emerging. Here, the embodiment of changing "discourse practices" (Gee, 1996) and the creation of a common discourse community might be viewed as an important condition for sustainable changes in professional cultures (Jenson et al., 2010).

\section{Engagement and persistence through knowledge-making}

Evidence of new learning partnership, new pedagogical capacities, and transformed learning outcomes (AP, Fullan and Langworthy, 2014) were often inextricable from teacher and student reports on engagement and increased agency. Almost every teacher saw the greatest advantage of innovative technology/pedagogy practices as lying in the richer tasks undertaken and the heightened engagement they generated, which fostered persistence in the face of challenges as well as greater initiative on the part of learners. When IBL practices were in play, almost every teacher interviewed indicated increased engagement (by contrast with traditional instruction methods), with many teachers signaling that engagement was "very high" or even "off the charts" (this held true for both high-performing students and students who typically struggled). Several teacher comments illustrate this:

- You could hear a pin drop sometimes when they're researching and to kind of poke yourself in there and interrupt them is not conducive to their thinking. I find that they're so focused when they're researching something, I don't have anybody this year who is off track.

- I can't tell you enough about the enthusiasm that they have and the focus that they have and just I really don't ever see anybody look bored or off track when it's inquiry based.

- So instead of finding an answer and being done, they're learning that there's more to be found out, and to stick with it.

Interwoven with heightened engagement was an accompanying expansion of students' sense of investment in learning as they were afforded greater latitude to codirect their own courses of inquiry. By a large margin, students also preferred engaging in inquiry projects: they found IBL projects were "more involving," "more interesting," "more challenging," and were connected with "problems in the world."

Indeed, engagement was reported to be very strong when students were researching "problems in the world." Almost two-thirds of inquiry projects invited students to address contemporary social issues at either a local or global level. Several focused on broad environmental issues such as pollution, species extinction, and global warming; a few were concerned with local social issues like indigenous activism and reconciliation. In one class, students were invited to identify social justice issues in their community or country, to research solutions, and then undertake some form of community action to address the matter politically. These kinds of projects - with corresponding reports of deepened engagement - provided evidence of student investment in learning practices where knowledge-making was situated in relation to authentic "matters of concern" (Latour, 2005; Ratto, 2011).
Transforming school culture 
JPCC

3,2

90

Teachers and students were also using network tools to research and share knowledge (on blogs or social media), as well as connect with other schools in North America to share perspectives and dialogue in real-time, or to bring external experts to the classroom. Further, having authentic audiences was part of new dynamic that charged rich tasks with value: students responded very positively when given opportunities to publish their work for external audiences. One teacher commented that the elation generated when some of his students had their videos posted on his YouTube channel was "like Christmas day [...] students loved the responses they got, and wanted to post more."

In surveys and interviews, most teachers felt that the majority of their students, when in engaged in IBL, developed richer understandings of the topics they researched than they would have under more conventional conditions. Teachers reported that students learned more deeply when involved in inquiry-driven projects, and that technology-meditated IBL provided opportunities for students to create knowledge and demonstrate more sophisticated competences than through standardized assessments. As one teacher reported: "[Students] feel as though they own their learnings and that is a strength that they've now developed for themselves. I think that is one of the biggest strengths [of the initiative]."

\section{iPads, collaborative learning, and new assessment forms}

In the data, reported increases in learning and engagement in IBL contexts were often inextricable from iPad use, and new ways of mobilizing technologies. Teachers reported that iPads, as research vehicles and creative tools, contributed to increased engagement/ enthusiasm and provided opportunities for students to enact multiple digital literacies in situ.

Students, too, strongly favored the creation of dynamic multimedia artifacts over text reports or posterboard presentations. While teachers permitted students to utilize non-digital media to demonstrate learning, many chose to use multimodal tools/literacies to represent knowledge or create alternative means of applying learning: the most commonly referenced apps included production-based tools like Explain Everything, iMovie, iBook-making software, multimodal slide decks (sometimes converted to video essays with voiceover or music soundtracks), with some use of games, simulations, and modeling tools (e.g., Minecraft). IPads were sometimes used as an imaginative medium for digital storytelling and artwork creation, as well as to facilitate multimodal artifact creation in interdisciplinary projects.

As evidence of a more heterarchical culture of learning, it was evident in interviews and in the student samples analyzed that students were very often invited to be active contributors to their own formative and summative "success criteria," indicating a shift away from the rigid, externally-imposed rubrics associated with standardized assessments. Jenson et al. (2016) have argued that, "if assessment systems largely prefigure what learning looks like, what is measurable, and therefore what is pedagogically possible, then transformations in learning environments must arrive with equally innovative assessment tools" (p. 21). Here, expressing new assessment practices, students were in the majority of classes taking roles as co-designers of their own outcomes, participating in developing formative "success criteria" (sometimes embedded in multimedia project themselves), and critically shaping project expectations (as and for learning). Upon completion of projects, students critically co-assessed their work in partnership with teacher/s and peers. In interviews and in samples analyzed, it was clear that summative assessment forms were also being mobilized, formatively, to refine future inquiry iterations. New tools were seen to provide richer opportunities for teachers to make observational assessments on the fly, with tools like Sesame Snap and GoogleDocs used to dialogue with students about progress in all stages of the IBL cycle. This offered evidence that teachers were devising new systems of assessment that were congruent with transformed practices and learning cultures. 
Consistent with Fullan and Langworthy's (2014) conceptualization of new learning partnerships, once student artifacts were completed, they would almost always be presented to the whole class. Students would then take the "role of the expert" to present their varying inquiry topics, findings and conclusions, and peers would offer critique. It was clear in most teacher interviews that collaboration and formative dialogue permeated almost every phase of inquiry - a key feature of twenty-first century competences.

When reflecting upon IBL and iPad use, many teachers reported that they were pleasantly surprised by unexpected outcomes, particularly when students were using new media to collaborate on, produce, and share culminating projects. Appreciation of "unexpected" results indicated that the predicted behavioral outcomes associated with traditional instruction were being gradually supplanted by more dynamic and personalized learning (a central goal of the action plan). In this context, one teacher reported that the initiative was "helping her become the teacher she always wanted to be." Another teacher, who was already using IBL, remarked that this was simply "good pedagogy." Importantly, teachers who were found to be the most enthusiastic about student engagement and the transformed products of learning were often the teachers most likely to be involved in building professional capital. Excitement about what students were doing and making appeared to feed-forward to drive further teacher networking, inquiry, and informal professional learning. Significantly, we saw evidence of a recursive, interactive relationship between classroom innovation and a wider collaborative professional-learning culture.

\section{Affordances of inclusivity}

Almost all of the teachers reported that 1:1 iPad use increased inclusivity and broadened who could participate in learning and communicative practices. Limitations in spoken and written language no longer discouraged student communication as those with needs in these areas often used assistive technologies to overcome barriers and share their learning. During research phases of inquiry, students with language-learning difficulties were often steered to apps that enabled them to circumvent dependence upon print-literacies. iPad-based digital books/texts were also used to bridge language boundaries for ELL students through interactive affordances that plaited text, image, sound, and audio in multimodal ensembles (Jewitt, 2008). In nearly every classroom, students were given latitude to select the tools/ modalities for representing learning and constructing culminating artifacts. Some teachers reported that this enabled a wider range of students, including those who may have formerly been excluded or assigned different work, to collaborate in whole-class learning processes, and this had an impact on their reported levels of engagement. IBL, too, was seen in some cases to support inclusion: as one teacher reported: "It's a huge advantage for knowledge development. We've got kids at different entry points with regards to their background knowledge and what they know, so kids having that freedom to go from wherever their own background knowledge is and explore from there is huge".

In these findings, we see an enactment of Jenson's et al. (2010) recommendation that "reform be built around the principles of inclusivity, equitable access, and the meaningful integration of ICT" (p. 19). Indeed, in relation to the district demographic data noted above (low income; a high percentage of residents with low post-secondary education), this initiative provides a compelling critical model for interrupting "the longstanding correlation between economic income and educational outcome" (de Castell, 2016), particularly for underserved communities, as these inclusive technology/pedagogy practices were supporting all learners with powerful twenty-first century competences.

Significantly, the initiative was increasing not just equitable access to digital tools/ literacies, but also inviting wider collaborative relations for all actors within pilot schools. Just as teachers reported that student collaboration was flourishing under new conditions,
Transforming school culture 
JPCC 3,2

it was evident from teacher interviews that informal professional collaboration and networked learning communities were also emerging, performatively mirroring the new pedagogies and learning partnerships being enacted in classrooms at the student level.

\section{Discussion: opportunities and challenges}

Research has shown that one condition for sustainable system change is eventuated when professional development/learning is embodied "as a holistic, ongoing formative feedback cycle with continuous collaboration at its center" (Fullan and Langworthy, 2014, p. 57). Based on our findings, we suggest, further, that pedagogical innovation and inquiry-driven work in classrooms - real changes in the practice of teaching and learning - can promulgate wider collaborative cultures, at every level of professional action. The very attributes of the pedagogical innovation, here, can become drivers of wider cultural shifts and transformed professional learning practices, led by inquiry-driven professional learning. In short, innovative pedagogies model dynamic forms of professional capital building (human, social, and decisional) which in turn, recursively, refine and extend opportunities for transformed classroom practices. If teachers reported that inquiry-driven technology/pedagogy practices, with knowledge-making at its core, fostered increased engagement, persistence, agency, and self-efficacy at the student level, then professional learning should be energized by the same supports and affordances.

By and large, we found compelling evidence of a synergistic relation between innovations in pedagogy and professional learning cultures, with evidence of increased collaborative actor agency - as well as increased engagement and a climate of risk-taking at all levels of pilot-school organization. At the same time, teachers were devising innovative assessment practices responsive to IBL and 1:1 $\mathrm{iPad}$ use, and innovations in pedagogy/technology practices were seen, overall, to promote richer, more inclusive applications of twenty-first century competences.

This is not to say that every actor in pilot schools uniformly embraced initiative aims: a small sample of teachers expressed some difficulties, especially during initial stages of implementation, with activating new tools and practices, or navigating tensions between new and old commitments. Also, among the teachers we interviewed, the extent and fidelity of IBL pedagogy implementation varied and, in our analysis, we found some evidence that deeper inquiry-driven learning was being mitigated by less adventurous, template-driven forms of IBL. This apparent templating of IBL tasks indicated that learning innovations were, in rarer cases, being neutralized and recuperated by traditional routines (with notably shallower results), especially when IBL processes were being translated into mechanical procedures for doing "web-searches" and reproducing propositional facts.

Here, we signal that one obstacle to transformative initiatives like the one reported here is a routinization of innovative pedagogy/technology practices. If deep learning forms are translated into mechanical processes, with more standardized assessments, professional learning, too, may become similarly attenuated. That is, if deep learning pedagogies are formularized, then professional capital building, as well as the excitement surrounding transformations, may also be enervated. In this context, healthy critical debate among practitioners on what system change might look like is preferable - and indeed valuable - by contrast with any formulaic ratification of new pedagogies.

To address this concern, we looked to those teachers in pilot schools who were, themselves, taking change-agent roles as researchers, and engaging the initiative as a collaborative, inquiry-driven enterprise (e.g. locating external models for practice while broadening their own capacities as teacher-researchers). In interviews, teachers clearly desired more professional support for optimizing inquiry-driven pedagogies, using iPads, and here we suggest that teachers might be supported to take roles as researchers, making linkages 
between new pedagogies and their content areas, and communicating their findings across classrooms and schools. By "doing" inquiry themselves, teachers will be in a stronger position to apprentice more sophisticated forms of inquiry for students - as well as introduce other forms of inquiry and knowledge-making interventions, for example, action-research, arts-based research, and/or ethnographic community explorations where learners might take researcher roles, equipped with more powerful investigative instruments and methods.

Further, if teachers become more fluent in inquiry practices, they will be able to intervene more strategically when it comes to instruction (e.g. they will be able to identify when/where direct instructional interventions are necessary, when/where background content knowledge is required, and consequently how to support connection-making to between IBL and the curriculum, as well as support student metacognitive reflection upon the competences students have acquired).

In the context our study, the alignment of inquiry-driven student learning with teacher-directed professional inquiry is reflexively consistent with initiative aims (AP). Inquiry-driven professional research, supported by networked technology tools, may offer a strategic practice for ongoing professional development/learning, where administrators, teachers and students collaborate, as a community, in amplifying the opportunities of pedagogical innovations.

\section{Conclusion: sustaining and scaling transformative initiatives}

If the drivers of system reproduction are ecological, embodied and encultured, then so must be the affordances of system transformation, if innovations are to be sustained. Indeed, as many researchers assert, today, schooling systems will likely reproduce themselves as long as teaching conforms to standardized forms of content instruction and assessment, and students remain mere reproducers of static knowledge and compartmentalized skills. Owston (2007) adds that, for innovations to take hold, teachers need to not only adopt new practices, they also must "unlearn" legacy beliefs about teaching and learning (p. 70). In the twenty-first century, this means creating pedagogical conditions, supported by technology tools, that position learners as capable and connected makers of knowledge and culture - in new learning partnerships with teachers.

While we found, in our analysis, obstacles that attenuated innovation, we found ample evidence of a transformed culture of learning, an embrace of new discourses and innovative practices, and a widespread enthusiasm for the initiative and its vision. We should note, too, that the kinds of holistic transformations articulated in the action plan do not occur overnight, and challenges are to be expected, particularly in the short term, when 1:1 technology tools and innovative pedagogies are first being engaged. That said, we found a vital learning culture was emerging in the pilot schools, supported by enthusiastic principals, teachers and students, who in turn were transforming teaching and learning in ways that significantly advanced the initiative's aims - even in its early stages.

Promisingly, our analysis indicated that students were indeed being positioned as knowledge co-creators - and teachers were similarly assuming new roles in building a dynamic professional learning culture. As a model for policy, what need be supported to sustain and scale initiatives like this one is this vibrant culture of professional capital building reported above: a culture that is actively supported by formal professional learning events and policies and, at the same time, is actively reenergizing itself through small-scale informal professional learning communities that build upon the excitement surrounding what students are imagining, making and doing. Finally, as with the best forms of inquiry-driven learning, transformative initiatives like this one, we feel, should be engaged not as a set of outcomes to be obtained, but enacted as an ongoing, creative process in which all actors in the ecology take part in collaboratively enriching initiatives they scale and circulate.

Transforming school culture 
JPCC
3,2

94

\section{Note}

1. Board Action Plan, Author Redacted, 2014 (hereafter cited in the text as AP).

\section{References}

Action Plan (2014), "District action plan: title and authors redacted for purposes of anonymity".

Canuel, R. (2013), "Innovation vs circulasticity”, Canada Education, Vol. 53 No. 5, pp. 24-25, available at: www.edcan.ca/articles/innovation-vs-circulasticity (accessed April 20, 2017).

Christensen, C.M., Horn, M.B. and Johnson, C.W. (2008), Disrupting Class: How Disruptive Innovation Will Change the Way the World Learns, McGraw-Hill, New York, NY.

Coburn, C.E. (2003), "Rethinking scale: moving beyond numbers to deep and lasting change", Educational Researcher, Vol. 32 No. 6, pp. 3-12.

Cope, B. and Kalantzis, M. (2009), “'Multiliteracies': new literacies, new learning”, Pedagogies: An International Journal, Vol. 3 No. 4, pp. 164-195.

Dawson, K. and Heinecke, W. (2004), "Conditions, processes and consequences of technology use: a case study", Technology, Pedagogy and Education, Vol. 13 No. 1, pp. 61-81.

de Castell, S. (2016), "Critical perspectives on '21st century education': theory and research", paper presented at International Association for Technology, Education and Development (IATED) Conference, Valencia, March 8.

de Castell, S., Bryson, M. and Jenson, J. (2002), "Object lessons: towards an educational theory of technology", First Monday, Vol. 7 No. 1, pp. 1-9, available at: http://firstmonday.org/ojs/index. $\mathrm{php} / \mathrm{fm} /$ article/view/923/845 (accessed August 24, 2017).

Dede, C. (2014), "The role of digital technologies in deeper learning, students at the center: deeper learning research series", Students at the Center: Jobs for the Future, pp. 1-25, available at: www. jff.org/sites/default/files/publications/materials/The-Role-of-Digital-Technologies-in-DeeperLearning-120114.pdf (accessed August 24, 2017).

Dede, C. (2015), “21st century students crave deeper learning”, EdTech, June 25, available at: https://edtechmagazine.com/k12/article/2015/06/21st-century-students-crave-deeper-learning (accessed August 24, 2017).

Dede, C. (2016), "Transforming education for the 21st century: the process of system scaling", paper presented at the Ontario Ministry of Education Fourth Annual 21st Century Teaching and Learning Roundtable, Toronto, February, available at: www.ontariodirectors.ca/ExecDir Newsletters/Dede\%20Scale\%20Ontario.pdf (accessed August 24, 2017).

Donohoo, J. (2017), "Collective teacher efficacy research: implications for professional learning”, Journal of Professional Capital and Community, Vol. 2 No. 2, pp. 101-116.

Drew, V., Priestley, M. and Michael, M.K. (2016), "Curriculum development through critical collaborative professional enquiry", Journal of Professional Capital and Community, Vol. 1 No. 1, pp. 92-106, available at: https://doi.org/10.1108/JPCC-09-2015-0006

Fixsen, D., Blase, K., Naoom, S. and Duda, M. (2015), "Implementation drivers: assessing best practices”, Report No. NIRN v. 5/2015, National Implementation Research Network, University of North Carolina, Chapel Hill, NC, available at: http://implementation.fpg.unc.edu/resources/ implementation-drivers-assessing-best-practices (accessed August 24, 2017).

Friesen, S. and Scott, D. (2013), "Inquiry-based learning literature review", available at: https:// inspiring.education.alberta.ca/wp-content/uploads/2014/04/Inquiry-Based-Learning-A-Reviewof-the-Research-Literature.pdf (accessed August 24, 2017).

Fullan, M. and Donnelly, K. (2013), Alive in the Swamp: ASSESSING Digital Innovations in Education, Nesta, London, available at: www.nesta.org.uk/publications/alive-swamp-assessing-digitalinnovations-education (accessed August 24, 2017).

Fullan, M. and Langworthy, M. (2014), A Rich Seam: How New Pedagogies Find Deep Learning, Pearson (with the support of ISTE: Always Learning Series), London, available at: www.michaelfullan. ca/wp-content/uploads/2014/01/3897.Rich Seam_web.pdf (accessed August 24, 2017). 
Gee, J.P. (1996), Social Linguistics and Literacies: Ideology in Discourses, 3rd ed., Routledge, New York, NY.

Hargreaves, A. and Ainscow, M. (2015), "The top and bottom of leadership and change", Phi Delta Kappan, Vol. 97 No. 3, pp. 42-48.

Hargreaves, A. and Fullan, M. (2012), Professional Capital: Transforming Teaching in Every School, Teachers College Press, New York, NY.

Hargreaves, A. and Fullan, M. (2013), "The power of professional capital: with an investment in collaboration, teachers become nation builders", Journal of Staff Development, Vol. 34 No. 3, pp. 36-39.

Hargreaves, A. and O'Connor, M.T. (2017), "Cultures of professional collaboration: their origins and opponents", Journal of Professional Capital and Community, Vol. 2 No. 2, pp. 74-85.

Hattie, J. (2015), What Works Best in Education: The Politics of Collaborative Expertise, Pearson, London.

Hattie, J.A. (2009), Visible Learning: A Synthesis of 800+ Meta-analyses on Achievement, Routledge, Abingdon.

Hébert, C. (2015), "(Student) teaching inside the box: stories of teaching and learning in and against the edTPA”, Unpublished doctoral dissertation, York University, Toronto.

Ito, M., Gutiérrez, K., Livingstone, S., Penuel, W., Rhodes, J. and Salen, K. (2013), Connected Learning: An Agenda for Research and Design, MacArthur Foundation, Chicago, IL.

Jenson, J., Taylor, N. and Fisher, S. (2010), "Critical review and analysis of the issue of skills, technology and learning", report submitted to The Ontario Ministry of Education, Toronto, available at: www.edu.gov.on.ca/eng/research/Jenson_ReportEng.pdf (accessed September 1, 2017).

Jenson, J., De Castell, S., Thumlert, K. and Muehrer, R. (2016), "Deep assessment: an exploratory study of game-based, multimodal learning in epidemic", Digital Culture and Education, Vol. 8 No. 1, pp. 21-40, available at: www.digitalcultureandeducation.com/volume-8/jense/ (accessed August 24, 2017).

Jewitt, C. (2008), "Multimodality and literacy in school classrooms", Review of Research in Education, Vol. 32 No. 1, pp. 241-267.

Kontopoulos, K.M. (1993), The Logics of Social Structure, Cambridge University Press, New York, NY.

Latour, B. (2005), Reassembling the Social: An Introduction to Actor-Network-Theory, Oxford University Press, New York, NY.

Lotherington, H. and Jenson, J. (2011), "Teaching multimodal and digital literacy in L2 settings: new literacies, new basics, new pedagogies", Annual Review of Applied Linguistics, Vol. 31, September, pp. 226-246.

Luke, A., Sefton-Green, J., Graham, P.W., Kellner, D. and Ladwig, J.G. (2017), "Digital ethics, political economy and the curriculum: this changes everything”, in Mills, K.A., Stornaiuolo, A., Smith, A. and Pandya, J.Z. (Eds), Handbook of Writing, Literacies and Education in Digital Culture, Routledge, New York, NY, pp. 251-262.

New London Group (1996), "A pedagogy of multiliteracies: designing social futures", Harvard Educational Review, Vol. 66 No. 1, pp. 60-93.

Nordkvelle, Y. (2004), “Technology and didactics: historical mediations of a relation”, Journal of Curriculum Studies, Vol. 36 No. 4, pp. 427-444.

Ontario Ministry of Education (2013), "Inquiry-based learning”, Capacity Building Series, available at: www.edu.gov.on.ca/eng/literacynumeracy/inspire/research/CBS_InquiryBased.pdf (accessed August 23, 2017).

Owston, R.D. (2007), "Contextual factors that sustain innovative pedagogical practice using technology: an international study", Journal of Educational Change, Vol. 8 No. 1, pp. 61-77.

Papert, S. and Harel, I. (1991), "Situating constructionism”, Constructionism, Vol. 36 No. 2, pp. 1-11.

Patton, M.Q. (1990), Qualitative Evaluation and Research Methods, SAGE Publications Inc., Beverly Hills, CA.

Peters, M.A. and Araya, D. (2010), "The creative economy: origins, categories, and concepts", in Araya, D. and Peters, M.A. (Eds), Education in the Creative Economy: Knowledge and Learning in the Age of Innovation, Peter Lang, New York, NY, pp. xiii-xxx. 
JPCC

3,2

Ratto, M. (2011), "Critical making: conceptual and material studies in technology and social life", The Information Society, Vol. 27 No. 4, pp. 252-260.

Strauss, A. and Corbin, J. (1990), Basics of Qualitative Research: Grounded Theory Procedures and Techniques, Sage, Newbury Park, CA.

Thumlert, K. (2015), "Affordances of equality: Rancière, emerging media, and the new amateur", Studies in Art Education, Vol. 56 No. 2, pp. 114-126, available at: www.tandfonline.com/doi/abs/ 10.1080/00393541.2015.11518955?journalCode $=$ usae20

Thumlert, K., De Castell, S. and Jenson, J. (2015), "Short cuts and extended techniques: rethinking relations between technology and educational theory", Educational Philosophy and Theory, Vol. 47 No. 8, pp. 786-803, available at: www.tandfonline.com/doi/abs/10.1080/00131857.2014.90 1163?journalCode=rept20

Toohey, K. and Dagenais, D. (2015), "Literacy in transcultural cosmopolitan times: a call for change", available at: werklund.ucalgary.ca/ltct/files/ltct/dagenais-toohey.pdf (accessed August 24, 2017).

Wei, R.C., Darling-Hammond, L., Andree, A., Richardson, N. and Orphanos, S. (2009), Professional Learning in the Learning Profession: A Status Report on Teacher Development in the United States and Abroad, School Redesign Network at Stanford University, National Staff Development Council, Dallas, TX, available at: https://learningforward.org/docs/pdf/ nsdcstudytechnicalreport2009.pdf?sfvrsn=0 (accessed August 20 2017).

Yin, R.K. (2006), "Case study methods", in Green, J.L., Camilli, G. and Elmore, P.B. (Eds), Handbook of Complementary Methods in Educational Research, Lawrence Erlbaum, Hillsdale, NJ, pp. 111-123.

Zeichner, K.M. (2002), "Teacher research as professional development for P-12 educators in the USA", Educational Action Research, Vol. 11 No. 2, pp. 301-326.

\section{About the authors}

Dr Kurt Thumlert is an Assistant Professor in the Faculty of Education at York University, Toronto, Canada. His research and teaching interests include technology studies, new media literacies, and production pedagogies, as well as curriculum theory and pedagogical innovation in twenty-first century learning contexts. He is an Executive Member of the Institute for Research on Digital Learning (IRDL) at York University. Dr Kurt Thumlert is the corresponding author and can be contacted at: kthumlert@edu.yorku.ca

Dr Ron Owston is a Professor of Education, a Former Dean of the Faculty of Education, and the Founding Director of the Institute for Research in Learning Technologies at York University, Toronto, Canada. In 2007, York University awarded him the honorary title of University Professor for his "extraordinary contribution to the University as a colleague, teacher, and scholar." A pioneer in teaching with the web since its early days, he specializes in the evaluation of technology-based educational programs in K12, government, higher education, and continuing professional education. He has spoken at numerous national and international conferences about blended and online learning, authored/co-authored some 50 commissioned studies, and published over 60 articles in refereed journals, including one of the first academic examinations of the role of the web for teaching and learning in Educational Researcher in 1997.

Taru Malhotra obtained her Bachelor's Degree in Science from Delhi University, and her Master's Degree in Education at York University. Currently, she is in the third year of her $\mathrm{PhD}$ program in the Faculty of Education at York University. Her research interests center around the use of technology and blended learning in classrooms, and she has worked on research projects evaluating how new technology is currently integrated in Canadian school boards. She also designed an intra-communication system for better supply chain integration in the private sector, and has worked extensively in coordination and training.

For instructions on how to order reprints of this article, please visit our website:

www.emeraldgrouppublishing.com/licensing/reprints.htm

Or contact us for further details: permissions@emeraldinsight.com 